ORIGINAL ARTICLE

\title{
The challenges of Otologic Practice in an emerging Otorhinolaryngological Unit at Federal Medical Centre, Makurdi
}

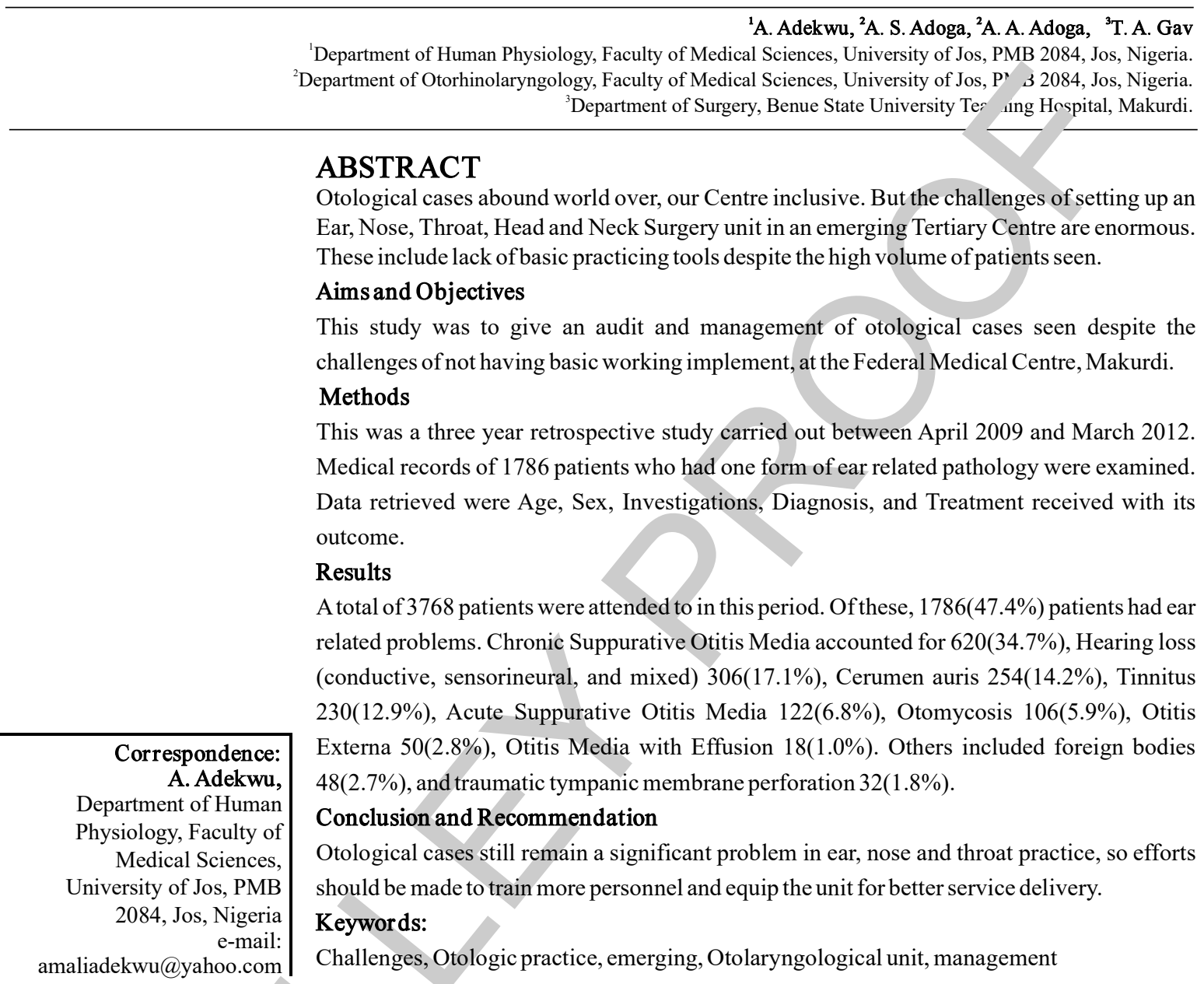

\section{INTRODUCTION}

Otology subspecia ty ${ }^{1}$ as w large volume of patients in most storhinolaryngological clinics wr ld ove $\mathrm{Th}$ i ia et al reported $60 \%$ of Otologic cases ir Otorhinolaryngological clinic attc Jance at Jos, Okafor (54\%) at Enugu, Salisu (56.27\%) at Kano and recently Fasunla et al reported $62.7 \%$ at Ibadan. Despite this high percentage of patients with otological problems, many Otorhinolaryngological clinics do not have functional otologic clinics because of the high cost of setting up such clinics in terms of diagnostic and therapeutic facilities. As a result of the dearth of otorhinolaryngologists in our country, the newly established Ear, Nose, Throat, Head and Neck unit of the Federal Medical Centre, Makurdi, caters for patients from Benue, Taraba, parts of Nassarawa, Cross-River and Kogi states. Makurdi is the capital of Benue State. The state has an area of about $34,059 \mathrm{~km} 2$ and is located in the North Central region of Nigeria. It has a population of about 5 million people who are mainly farmers, civil servants and traders. Otologic practice in developing countries has remained unsatisfactory. It is worse in an emerging center like ours where inadequate funding and lack of skilled manpower aggravate the challenges. 
The aim of this study is to highlight the management challenges of otological cases seen at the Federal Medical Center, Makurdi, in spite of lack of diagnostic and therapeutic facilities. It is hoped that this knowledge will create better awareness that will lead to improved practice of otology in our environment.

\section{MATERIALSAND METHODS}

This is a three-year retrospective study spanning from April 2009 to March 2012. The study was designed to audit otological cases and their Management Challenges, at the Otorhinolaryngological clinic of the Federal Medical Center, Makurdi. Ethical clearance for the study was obtained from the ethical committee of the hospital. The medical records of these patients were examined. The data retrieved included age, sex, investigations done-audiometric assessments, $\mathrm{x}$-rays and computed tomographic (CT) scan findings (where available), clinical diagnosis, treatment modality and its outcome. These data were analyzed using Microsoft Excel 2007 and presented in simple descriptive forms.

\section{RESULTS}

A total of 3768 patients were attended to in this period. Of these, 1786(47.4\%) patients had ear related problems. There were 964 males and 822 females, giving a sex ratio of $1.2: 1$. The age range was from 6 months to 80 years with patients aged below 10 years accounting for $41.2 \%$ [Table1].

The most frequently encountered otologic condition was Chronic Suppurative Otitis Media (CSOM), which was found in $620(34.7 \%)$, hearing loss (conductive, sensorineural, and mixed) 306(17.1\%), cerumen auris $254(14.2 \%)$, tinnitus $230(12.9 \%)$, acute suppurative otitis media (ASOM) 122(6.8\%), Otomycosis 106(5.9\%), Otitis externa 50(2.8\%), and Otitis media with effusion $18(1.0 \%)$. Others included foreign bodies $48(2.7 \%)$, and traumatic tympanic membrane perforation 32(1.8\%) cases. [Table2].

Ear cultures of CSOM patients yielded predominantly Pseudomonas aeroginosa (74.6\%), streptococcus spp (13.5\%) while for ASOM , the culture grew_Streptococcus pneumonia $(58.2 \%)$ and Haemophilus influenza $(46.3 \%)$, and in Otomycosis, Aspergillus niger $(69.7 \%)$ and candida albicans $(23.9 \%)$ were isolated. Pure tone audiograms ( PTA) were obtained in $554(31.0 \%)$ while tympanometry was performed on $418(23.4 \%)$ patients. Out of this number, $468(84.5 \%)$ had benefit from hearing aid evaluation but only $195(41.7 \%)$ patients were able to procure them. Only 130 patients had X-ray mastoids done with cavitation seen in 4. Eight had acute mastoiditis.

We undertook 408 clinic procedures of which ear syringing for cerumen auris and otomycosis accounted for (238) 58.3\% and foreign body extraction (89) $21.8 \%$. Others were chemical cauterization of aural polyps and ear wick dressing for CSOM (81) 19.9\%.

Theatre procedures were performed on 118 patients $(6.6 \%)$. These were external ear procedures, such as impacted foreign bodies, keloid excision, pinnae repair and mastoid abscess drainage.

Table 1: Age range of patients with ear disease

\begin{tabular}{|c|c|c|}
\hline $\begin{array}{c}\text { Age } \\
\text { (years) }\end{array}$ & $\begin{array}{c}\text { Number of } \\
\text { Cases }\end{array}$ & Percentage \\
\hline$<10$ & 735 & 41.2 \\
\hline $11-20$ & 312 & 17.5 \\
\hline $21-30$ & 406 & 22.7 \\
\hline $31-40$ & 183 & 10.2 \\
\hline $41-50$ & 67 & 3.8 \\
\hline $51-60$ & 49 & 2.7 \\
\hline $61-70$ & 25 & 1.4 \\
\hline $71-80$ & 9 & 0.5 \\
\hline Total & 1786 & 100 \\
\hline
\end{tabular}


Table 2: Most frequently encountered Otologic condition

\begin{tabular}{lcc}
\hline Otologic disease & $\begin{array}{c}\text { No. of } \\
\text { cases }\end{array}$ & Percentage \\
CSOM & 620 & 34.7 \\
Hearing loss & 296 & 16.6 \\
Cerumen auris & 239 & 13.4 \\
Tinnitus & 214 & 12.0 \\
ASOM & 122 & 6.8 \\
Otomycosis & 106 & 5.9 \\
Otitis externa & 50 & 2.8 \\
OME & 18 & 1.0 \\
FB & 89 & 5.0 \\
Traumatic TM & 32 & 1.8 \\
perforation & 1786 & 100 \\
Total & & \\
\hline
\end{tabular}

\section{DISCUSSION}

Varieties of cases present to our Otorhinolaryngological clinic. Otological cases 1786(47.4\%) constituted the highest ENT Clinic attendance in our Centre. This agrees with findings of Bhatia et al ${ }^{1}(60 \%)$, Okafor $^{2}(54 \%)$, Salisu ${ }^{3}$ (56.27\%) and Fasunla et $\mathrm{al}^{4}(62.7 \%)$. Though our percentage is lower than theirs, they reported otological attendees were more in their Otorhinolaryngological Clinic visitation. The higher percentage might have arisen from their larger sample size and longer research period of four years and above.

Chronic Suppurative Otitis Media (CSOM) was the commonest otological condition encountered in our Centre. It accounted for $34.7 \%$ and $98 \%$ of these were tubotympanic type. This is similar to findings by Okafor (44.8\%) at Enugu and Salisu (25.4\%) at Kano.
Pseudomonas aeroginosa was the predominant isolate in the CSOM. This finding concurs with that of Salisu ${ }^{3}$ and Nwankwo et $\mathrm{al}^{5}$ in Kano, Coker et $\mathrm{al}^{6}$ in Ibadan and Brobby et $\mathrm{al}^{7}$ in Accra, Ghana.

We found Aspergillus niger in $69.7 \%$ and Candida albicans in $23.9 \%$, which still remain important fungi in otomycosis as alluded to by previous reports by Gugnani et $\mathrm{al}^{8}$ and Mgbor et $\mathrm{al}^{9}$ in Enugu, and Tang et $\mathrm{al}^{10}$ in Houston, Texas. However this finding contrasts with that of Yavo et $\mathrm{al}^{11}$ in Abidjan, Cote d'Ivoire who reported Aspergillus flavus as the commonest etiologic agent. There are many topical antifungals with proven efficacy ${ }^{12,13}$. But in our Centre, both Mercurochrome and Candibiotic ear drops were used with very good effect resulting in over $90 \%$ cure rate. This agrees with the report of Mgbor et $\mathrm{al}^{9}$ but differs from that of Tang et $\mathrm{al}^{10}$ who used ketoconazole cream with more than $80 \%$ resolution rate.

Cerumen auris $(14.2 \%)$ are still common and were managed by manual removal and gentle ear syringing. FB attendees were low $(5.0 \%)$ but the challenge was failed attempted removal or extraction at home or peripheral Centers with attendant trauma to the ear resulting in surgical intervention. This in our own study accounted for about $92 \%$. Okafor reported $12 \%$ of FB attendees while Salisu found $7.3 \%$ in their studies. Whereas their percentages were higher than ours probably because of their larger sample sizes, they alluded to the 
challenge of ear trauma occasioned by failed attempted removal at home or peripheral centers. Okafor encountered $82 \%$ of such ear trauma cases but Salisu did not quantify his own.

Hearing loss was the second commonest encountered in our Clinic. It accounted for $16.6 \%$ with SNHL accounting for $85 \%$. The causes were cerebrospinal meningitis (79\%), drug ototoxicity $(15 \%)$. This agrees with the findings of Salisu at Kano and Fasunla et al at Ibadan, though Fasunla et al did not quantify their findings. Cerebrospinal meningitis appears to have a high prevalence in Benue and some neighboring states because of the high temperature, nearly all year round and overcrowded houses with poor ventilation. Hearing loss has a significant burden in developing countries ${ }^{8,9}$. Despite this great burden, many medical facilities do not have audiological assessment equipment. This constitutes our greatest challenge, as patients had to travel about $300 \mathrm{kms}$ to get to a hospital with audiological assessment facility. Only $41.7 \%$ of patients who needed hearing aids could afford them due to financial constraints. Some of those who acquired one discontinued, complaining of no further benefit, damage or lack of maintenance points. Many of our tinnitus sufferers described high-frequency tone worse during bedtime or at night. Many of them benefitted from Betahistine (Serc16) medication as against tinnitus retraining therapy (TRT) which they complain is cumbersome with delayed or no appreciable benefit. Others could not afford the drug because of its high cost.

\section{CONCLUSION/ \\ RECOMMENDATION}

Otological cases still remain a significant problem in ear, nose and throat practice, so efforts should be made to train more personnel and equip the unit for better service delivery and subsidize some audiological consumables.

\section{REFERENCES}

1. Bhatia PL, Varughese R. Pattern of otolaryngological diseases in Jos community. Niger med J 1987; $17: 67-83$

2. Okafor BC, Otolaryngological diseases of South Eastern Nigeria: pattern of diseases of the ear. Niger Med J 1983: 13;11-9

3. Salisu AD. Otology practice in a Nigerian tertiary health institution: A 10-year review .Annals of African Medicine vol.9 No 4:2010;218-21

4. Ayotunde James Fasunla, Musa Samdi, Onyekwere George Nwaorgu. An audit of Ear, Nose and Throat diseases in a tertiary health institution in South-western Nigeria. The Pan African Medical Journal. 2013;14:1

5. Nwankwo AO, Salisu AD. Bacteriology of chronic discharging ears of patients in Kano, Nigeria. J Med Lab Sci2005:14;57-62

6. Coker OA, Ijaduola GT, Odugbemi TO. Bacterial isolates from chronic discharging ears in Nigeria children. 
A.Adekwu et al: The challenges of Otologic Practice in an emerging Otorhinolaryngological Unit

Niger med pract 1982:4;170-4

7. Brobby GW. The discharging ears in the tropics: A guide to diagnosis and management in the district Hospital. Trop Doct 1992; 22:10-3

8. Gugnani H.C, Okafor B.C, Nzelibe F, Njoku-Obi A.N.U. Etiological agents of Otomycosis in Nigeria. Mycoses 32(5) 224-229.

9. Mgbor Nnennia, Gugnani H.C. Otomycosis in Nigeria: treatment with mercurochrome. Mycoses 44, 395-397 (2001)

10. Tang Ho, Jeffrey T.V, Donald Yoo, Newton J.C. Otomycosis: Clinical features and treatment implications. Otolaryngology-Head and Neck
Surgery (2006) 135, 787-791.

11. Yavo W, Kassi R.R, Kiki-Barro P.C, Bamba A, Kple T, Menan E.I, Ehouo F, Kone M. Prevalence and risk factors for Otomycosis treated in the hospital setting in Abidjan ( Ivory Coast). Med Trop (Mars). 2004; 64(1):39-42.

12. Bassiouny A, Kamel T, Moawad M.K, Hindawy D.S. Broad spectrum antifungal agents in Otomycosis. J Laryngol Otol. 1986.100:867-73.

13. Stern J.C, Shah M.K, Lucente F.E. In vitro effectiveness of 13 agents in Otomycosis and review of the literature. Laryngoscope. 1988. 98:1173-7.

CALIPHATE MEDICAL JOURNAL Vol. 2 No. 4, October - December 2014, ISSN: 2346-7 193

194 